\title{
EL USO DE LOS PERMISOS PARENTALES POR LOS HOMBRES Y SU IMPLICACIÓN EN EL CUIDADO DE LOS NIÑOS EN EUROPA ${ }^{1}$
}

\section{MEN'S USE OF PARENTAL LEAVES AND THEIR INVOLVEMENT IN CHILD CARE IN EUROPE}

https://doi.org/10.17979/relaso.2011.1.1.1196

\section{Gerardo Meil}

Universidad Autónoma de Madrid

\section{Resumen}

En la última década los poderes públicos han fomentado el uso de los permisos parentales por parte de los hombres como un nuevo mecanismo para fomentar la igualdad de género y la no discriminación por razón de maternidad. En este trabajo se analiza a partir de la encuesta europea de condiciones de trabajo de 2005, recurriendo a la submuestra correspondiente a padres de hijos menores de 8 años, si efectivamente el uso de los permisos parentales por los hombres se traduce en una mayor implicación en el cuidado de sus hijos y en el trabajo doméstico. A partir de un análisis de regresión logística en el que se controla por distintas características del trabajo, la situación familiar y el nivel educativo, los resultados confirman que los hombres que han hecho uso del permiso parental en el año previo a la encuesta están más frecuentemente implicados en el cuidado diario de los niños y en la realización del trabajo doméstico que quienes no han hecho uso de esta posibilidad. El uso por los hombres del permiso parental se evidencia asi como un mecanismo que promueve su socialización en las tareas de cuidado no remunerado.

\footnotetext{
${ }^{1}$ Este trabajo forma parte del proyecto de investigación "El uso social de los permisos parentales en España" financiado por la Dirección General de Investigación Científica, Ministerio de Ciencia e Innovación, ref. CSO2009-11328, a quien el autor agradece el apoyo recibido.
} 


\section{Abstract}

During the last decade, policy developments in the field of parental leave have tended to promote actively men's use of this kind of leave as a way for promoting a greater gender equality. Using the European working conditions survey 2005, in particular the subsample of fathers with children less than 8 years old, this article analyses the research question if men's use of parental leave is related with a greater involvement in childcare and housework. Based on a binomial logistic regression, controlling for different aspects of work conditions, family situation and educational level, results show a positive relationship between men's use of parental leave in the year previous to the survey and daily childcare and housework involvement. Men's use of parental leave seems then to be an effective mechanism of men's socialization in care activities.

Palabras clave: permisos parentales, igualdad de género, cuidado de niños, trabajo doméstico, conciliación de vida familiar y laboral, trabajo no remunerado, unión europea

Key words: parental leave, gender equality, childcare, housework, work-family balance, non paid work, European Union

\section{Introducción}

El permiso de maternidad tiene una larga tradición, pues los primeros permisos datan ya de comienzos del siglo XX. En España, concretamente, se introducen con la creación del seguro de maternidad en 1931. La razón de estos permisos era facilitar asistencia médica y la recuperación de la madre tras el parto a fin de garantizar la salud tanto de la madre como del recién nacido. Durante la mayor parte del siglo XX, los permisos laborales vinculados al nacimiento de los hijos se concibieron exclusivamente para las madres trabajadoras y estuvieron diseñados bien para servir a las necesidades del 
mercado de trabajo durante períodos de escasez de mano de obra facilitando el retorno de las madres al trabajo tras el parto (por ejemplo, durante la segunda guerra mundial en Estados Unidos -Seward et al., 2006-), bien para contribuir a la difusión del modelo de familia conocido como "ganapán" (male breadwinner family model), burgués o "tradicional", fomentando excedencias prolongadas pero sin remuneración ni garantía de mantenimiento del puesto de trabajo.

No será hasta los años 70 , en los países escandinavos, cuando se produzca un cambio de enfoque en dirección hacia su concepción como un recurso para promover la conciliación de la vida laboral y familiar y la igualdad de género (Lappegard, 2008; Duvander, Lappegard y Anderson, 2010; Escobedo, Flaquer y Navarro, en prensa). Esta motivación igualitaria se sustanció primero en la extensión del derecho a los permisos (inicialmente exclusivos de las mujeres) a los hombres, pudiendo ser utilizados indistintamente por hombres y mujeres una vez pasado un plazo de recuperación obligatoria para las mujeres tras el parto. Dado que la libertad de elección no se tradujo en una mayor utilización de los permisos parentales por parte de los hombres, puesto que la proporción de padres que interrumpian su trabajo más allá de un par de dias tras el nacimiento de un hijo era extremadamente baja, y que este uso diferencial de los permisos contribuye al reforzamiento de la discriminación hacia las madres, se comienzan a diseñar en los 90, también inicialmente en los países escandinavos, incentivos específicos para que los hombres utilicen los permisos parentales, arbitrándose una "cuota de permiso" específica para los padres (Kvande, 2007; Lappegard, 2008; LammiTaskula, 2008). Así, en 1993 se introduce en Noruega y en 1995 en Suecia un permiso de un mes con un salario de sustitución elevado exclusivo para el hombre, de forma que si no lo utiliza, no puede ser transferido a la madre (Duvander, Lappegard y Anderson, 2010). El objetivo de estos permisos es desfeminizar el uso de los permisos parentales y fomentar la igualdad de oportunidades de hombres y mujeres, de forma que la maternidad y la utilización de los permisos parentales 
como un recurso para conciliar vida familiar y laboral no se traduzcan en discriminación en el mercado de trabajo, ya sea perdiendo el empleo, o bien frenando o imponiendo un techo de cristal a la promoción profesional de las madres (Burgess et al., 2008).

El objeto de este trabajo es analizar si el uso de los permisos parentales por parte de los hombres está asociado a una mayor implicación de éstos en el cuidado de los niños y, más en general, si contribuye a un reparto más igualitario del trabajo reproductivo o no remunerado que se realiza en las familias. El artículo se estructura en los siguientes apartados. En un primer apartado se presentan las principales características de los permisos parentales en los países desarrollados y las tendencias de cambio. En el segundo apartado se realiza la revisión bibliográfica sobre el efecto del uso de los permisos por los padres (varones) sobre su participación en el cuidado de los hijos y en las tareas del hogar. A continuación se presentan las características de la encuesta europea de condiciones laborales, la estrategia de análisis y finalmente se discutirán los resultados.

\section{Caracteristicas de los permisos parentales en los países desarrollados}

Los permisos o licencias del trabajo derivadas del nacimiento, adopción o acogimiento de niños son muy diversos en los países desarrollados, no sólo en su denominación, sino sobre todo en lo que se refiere a su configuración. Inicialmente limitados únicamente al permiso de maternidad, en la actualidad incluyen también un permiso de paternidad, ambos estrechamente vinculados al parto $o$ a la incorporación al hogar por adopción o acogimiento de un niño, más una prolongación voluntaria de estos permisos que se conoce con el nombre de permiso parental en la terminología inglesa (OCDE, 1995; Moss y O`Brien, 2006, Moss, 2010) y que tiene su equivalente en la legislación española en la excedencia por cuidado de niños. La frontera entre estos tres permisos está diluyéndose cada vez más, 
sobre todo en los países escandinavos, al tenderse a ampliar la duración del permiso bien remunerado de maternidad y paternidad, al tiempo que se introducen incentivos para que los hombres utilicen estos permisos y se reduce la duración del permiso parental (excedencia) (Moss y Wall, 2007, Moss, 2010, Duvander, Lappegard y Anderson, 2010). Así, en algunos países, singularmente los escandinavos y Portugal, la legislación no recoge los tres tipos de permisos como figuras legales específicas, sino que establece un permiso parental genérico, donde hay un periodo obligatorio para la madre, otro obligatorio para el padre y uno tercero que pueden dividirse entre los progenitores como deseen (Moss, 2010). El ejemplo más claro de esta concepción es la reforma introducida en Islandia que establece 3 meses para la madre, 3 para el padre y 3 adicionales a determinar por los progenitores (Einarsdóttir y Pétursdóttir, 2011); la introducción a partir de 2011 de un derecho universal para todos los asalariados en Australia a un permiso parental parcialmente remunerado tampoco prevé un permiso de maternidad propiamente dicho, sino que éste está integrado dentro de la normativa que regula el permiso parental (Alexander, Whitehouse y Brennan, 2011). Por otra parte, estos permisos no sólo se aplican al cuidado de los niños, sino de forma creciente también para facilitar el cuidado de familiares dependientes.

Además de estos tres permisos, según los países, hay también "permisos por cuidado de niños" (childcare leave), que son una extensión del permiso parental (excedencia) en aquellos países en los que éste no tiene una duración elevada, dias libres en casos de enfermedad, permisos por riesgo durante el embarazo (diferentes del permiso de maternidad), así como el reconocimiento al derecho a reducir la jornada de trabajo (que en algunos países se considera como una forma de flexibilización del uso del permiso parental) o/y el derecho a flexibilidad horaria (Moss, 2011).

Las principales dimensiones en las que difieren las legislaciones nacionales sobre los permisos, además de los 
tipos de permisos que se establecen, son la duración, la remuneración durante el permiso, la flexibilidad en el uso y la posibilidad de reparto entre los progenitores de los permisos. Las posibilidades de combinación son muchas y no hay ninguna legislación que sea igual de un país a otro (cf. Moss, 2011). Los países de la Unión Europea, no obstante, están obligados al establecimiento de unos requisitos mínimos en cuanto al permiso de maternidad y al permiso parental (excedencia), en virtud de las directivas 92/85/EEC de 19 Octubre 1992 sobre medidas para la mejora de la seguridad y la salud de las trabajadoras embarazadas, que han dado a luz o que se encuentran amamantando a sus hijos, así como de la directiva 2010/18/EU sobre permisos parentales de 8 de marzo de 2010 (que mejora la directiva de 1996/34/EC) y que tiene que ser traspuesta a la legislación nacional por los estados miembros antes de marzo de 2012.

\section{Gráfico 1}

Semanas de baja por maternidad según sean remuneradas o no en los países de la OCDE, 2007/2008

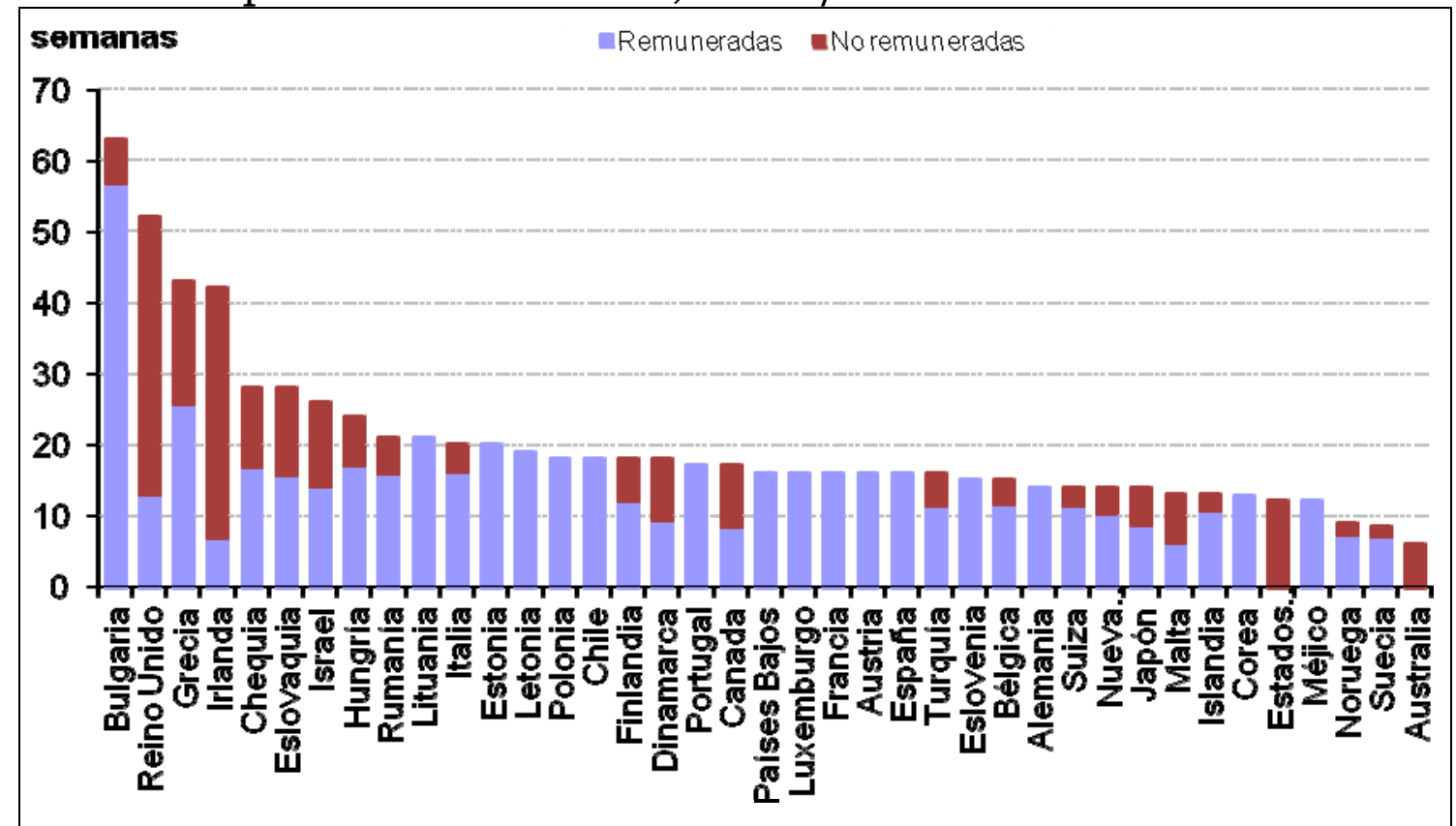

Notas: La remuneración corresponde al equivalente en semanas remuneradas al $100 \%$ del salario. 
Fuente: OECD, Family Database www.oecd.org/els/social/family/database, acceso el 6 de octubre de 2011.

En cuanto al permiso de maternidad, la duración varía mucho de un país a otro, como varía también el porcentaje de salario de sustitución que se recibe. Así, en el ámbito de la OCDE y como puede verse en el gráfico1, la duración va desde 63 semanas en Bulgaria remuneradas al 90\% del salario, lo que significa 56,7 semanas al $100 \%$, hasta 6 semanas sin compensación alguna en Australia (si bien a partir de enero de 2011, hay derecho a 18 semanas remuneradas al nivel del salario mínimo, lo que representa aproximadamente el $50 \%$ del salario medio -Alexander, Whitehouse y Brennan, 2011-). Estados Unidos destaca por no prever remuneración alguna a escala nacional para el período reconocido (sólo reconoce una baja por enfermedad o situación familiar -family and medical leave- sin remuneración alguna para las empresas con más de 50 empleados), aunque los convenios colectivos suelen prever algún tipo de salario de sustitución. La directiva 92/85/EEC de la Unión Europea establece un mínimo de 14 semanas para todos los países de la Unión, si bien la mayoría de países establecen un período de disfrute más amplio, siendo especialmente elevado en el Reino Unido (52 semanas), Grecia (43), Irlanda (42), Chequia (28) y Eslovaquia (28 semanas). No obstante, el salario de sustitución previsto varia mucho menos, pues en los países en los que se establece un período prolongado de descanso postparto, no todas las semanas dan derecho a un salario de sustitución, o la cuantía del mismo va disminuyendo a medida que se prolonga el permiso. En relación a la posibilidad de utilización por parte de los hombres de parte del permiso de maternidad, solamente en Chequia, Croacia, Polonia, España y el Reino Unido existe esta posibilidad como un derecho de todos los trabajadores independientemente de cualquier circunstancia; en los demás países está sujeto a restricciones muy estrictas, tales como muerte de la madre (Moss, 2011). En los países escandinavos se ha sustituido el derecho a 
compartir el permiso de maternidad por un período específico para los hombres ("mes/meses del papá").

Gráfico 2

Semanas de baja por paternidad según sean remuneradas o no en los países de la OCDE, 2007/2008

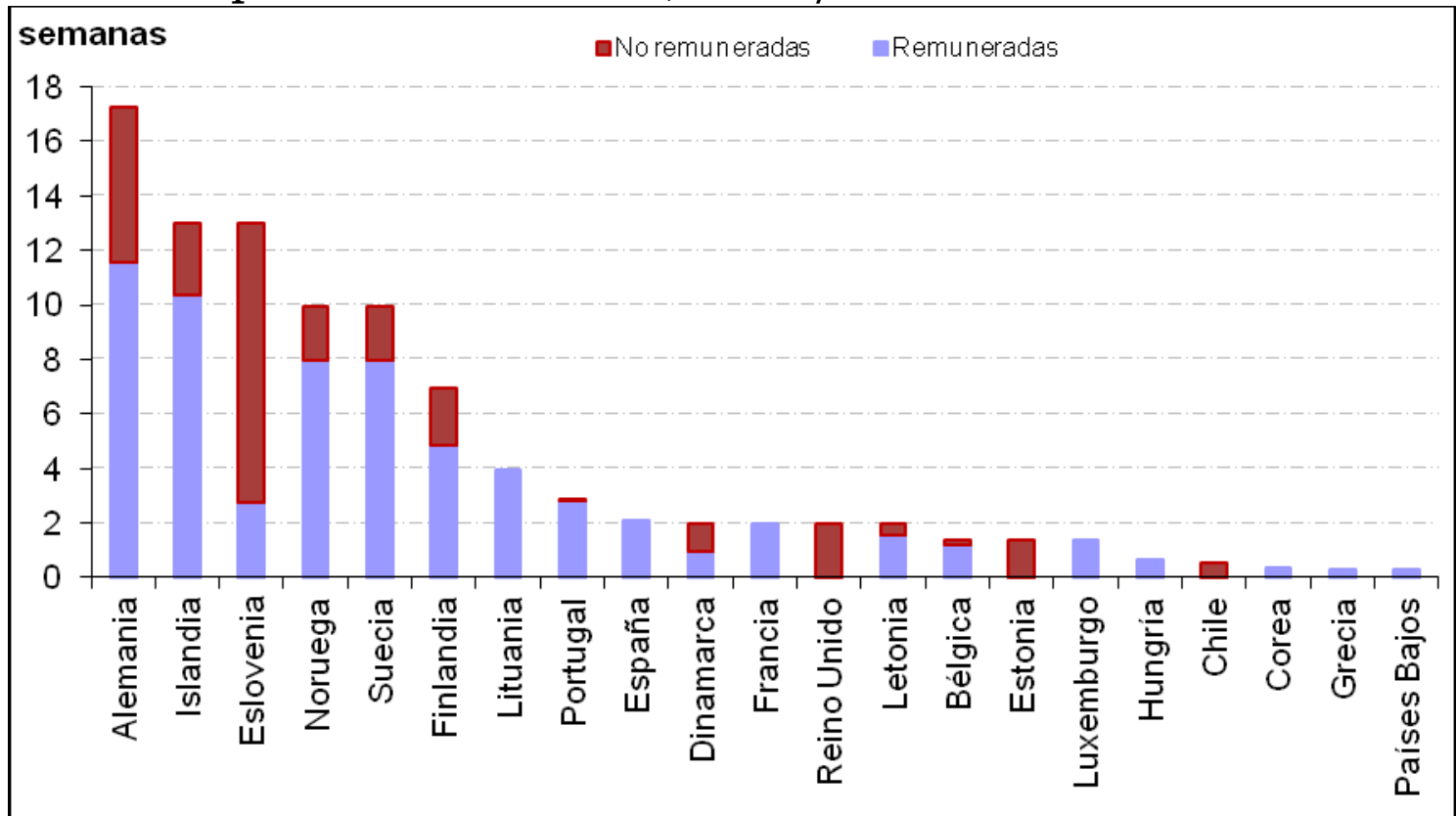

Fuente: OECDm $\quad$ Family Database www.oecd.org/els/social/family/database, acceso el 6 de octubre de 2011.

El permiso de paternidad está mucho menos extendido que el de maternidad; de hecho, únicamente 19 de los 30 países que integran la OCDE reconocen de alguna manera el derecho a días libres derivados de la paternidad. Junto a los países que figuran en el gráfico 2, la provincia de Quebec también reconoce de 2 a 5 semanas (Moss, 2010). El tiempo reconocido varía mucho de un país a otro, yendo desde 2 días en Grecia y los Países Bajos hasta 17,3 semanas en Alemania, aunque sólo 11,6 semanas son remuneradas. En algunos países como Portugal, Finlandia o la provincia de Quebec en Canadá, la duración del permiso se amplía cuando los hombres han utilizado todo el permiso en determinadas condiciones. En general, el salario de sustitución que se 
establece es el mismo que en el caso de maternidad y varía desde el $100 \%$ del salario hasta la ausencia de remuneración o remuneración de cuantía fija baja en determinadas circunstancias. En todos los países este permiso es intransferible a la madre y su razón de ser, cuando se trata sólo de unos días, es la de apoyar a la madre tras el parto y en los casos de mayor duración, se integran, como se ha señalado, dentro de una política de fomento de la igualdad de género. Los criterios de flexibilidad introducidos habitualmente en los permisos más largos establecen la posibilidad de utilizar este permiso no en el momento del parto, sino una vez concluido el permiso de maternidad o en algún momento hasta que el hijo que da derecho al permiso cumple determinada edad (habitualmente los 8 años), como sucede en los países escandinavos (Duvander, Lappegard y Anderson, 2010).

Casi todos los países de la OCDE prevén además de los referidos permisos, un permiso parental más amplio una vez concluido el permiso de maternidad, siendo la excepción África del Sur, Suiza y Estados Unidos (Moss, 2011). La duración del permiso parental (excedencia) una vez concluido el permiso de maternidad varia entre 156 semanas en Polonia y 13 semanas en países como Portugal, Bélgica, Reino Unido e Irlanda, estando los países de la Unión Europea obligados a reconocer al menos 3 meses ( 4 meses a partir de 2012) en virtud de las directivas anteriormente referidas. La remuneración durante el tiempo del permiso es muy variable de un país a otros, yendo desde la ausencia de compensación alguna por la pérdida de salario hasta salarios de sustitución por encima del $66 \%$ del salario previo al permiso. La mayor parte de los países, como puede verse en el gráfico 3, prevén algún tipo de compensación. De hecho, la utilización de estos permisos es tanto más frecuente cuanto mayor es el grado de compensación económica (Moss y Wall, 2007; Moss, 2010). 
Gráfico 3

Semanas de permiso parental (excedencia) según sean remuneradas o no en los países de la OCDE, 2007/2008

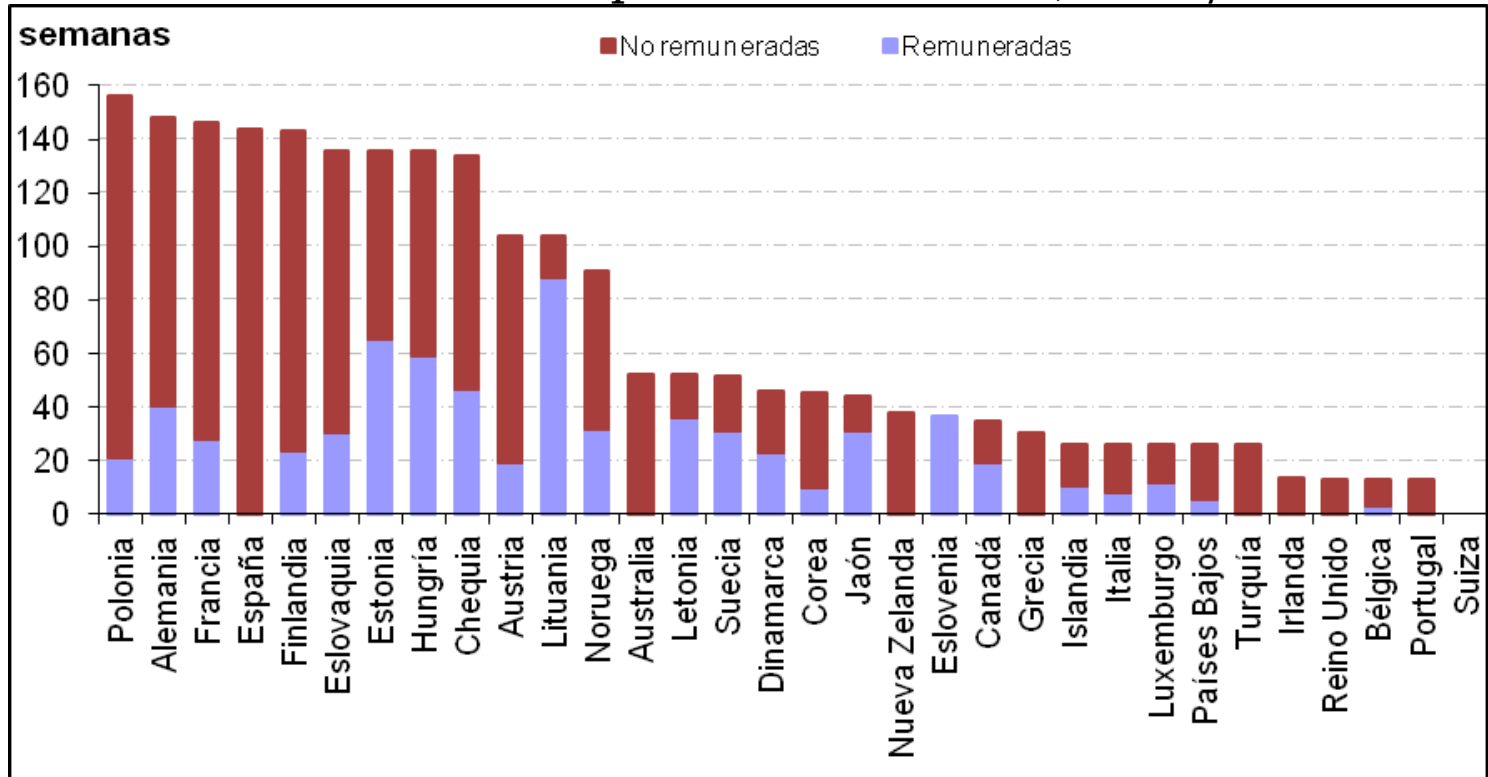

Fuente: OECD (2007) Family Database www.oecd.org/els/social/family/database, acceso el 6 de octubre de 2011

Las tendencias de cambio que se han registrado en la última década han sido resumidas por S. Kamermann (cit. en Moss y Wall, 2007) en los siguientes términos:

- Creciente complejidad y diversidad de los permisos, lo que conlleva que resulten dificiles de comprender y de gestionar.

- El diseño de los permisos está cada vez más influido por los objetivos de las políticas de bienestar infantil, género y de mercado de trabajo.

- Tendencia a prolongar la duración de los permisos, si bien al respecto hay que indicar que esta tendencia se refiere a los permisos postparto (maternidad y paternidad), mientras que en lo que se refiere a los permisos parentales (excedencia) la tendencia es hacia hacerlos más cortos pero mejor remunerados, como lo evidencian las reformas acometidas en los últimos años en Alemania e Islandia. 
- Incentivación del uso por parte de los padres (varones) de los permisos, bien estableciendo cuotas intransferibles a la madre o ampliando la duración de los permisos de paternidad, bien aumentando el salario de sustitución, bien fomentando la transferibilidad de los permisos para las madres hacia los padres.

- Creciente preocupación por la caída de la fecundidad y sus consecuencias.

- Creciente conciencia de que es necesario articular la política de permisos parentales con la oferta de servicios educativos y de cuidado de los niños preescolares.

- Emergencia de mecanismos de compensación económica por el cuidado en el hogar, enmarcados en una política de orientación conservadora de facilitación de la "libertad de elección" de los padres entre el cuidado de los niños en casa o en centros.

- Relativa poca consideración de los derechos de los niños a la hora de rediseñar la política de permisos parentales.

Aunque con retrasos debido a la crisis económica (como, por ejemplo, la no ampliación a 4 semanas en la fecha prevista del permiso de paternidad en España o el retraso hasta 2013 de la introducción de este permiso en Australia; la no ampliación a 18 semanas del permiso de maternidad en la Unión Europea), estas tendencias siguen siendo válidas para el período posterior a 2007 en que se identificaron.

\section{Efectos del uso de los permisos parentales sobre la implicación de los padres en el cuidado de sus hijos}

Como se ha indicado más arriba, la razón principal para introducir los permisos parentales para los hombres es fomentar la igualdad de género (Burgess et al.,2008), pero no sólo en el ámbito del trabajo remunerado, sino también en el ámbito del trabajo no remunerado. Junto a esta motivación, también se ha argumentado a favor de la introducción de permisos parentales específicos para los hombres porque se espera que sirvan para su socialización en el cuidado de los hijos y les dediquen más tiempo y atención, dados los efectos 
positivos que ello tiene en el desarrollo de su personalidad (Lamb, 1997). También se ha justificado la necesidad de una mayor implicación de los hombres en el cuidado de los niños por la reducción del tiempo disponible de las madres para su cuidado como consecuencia de su incorporación al trabajo remunerado. En este sentido, la justificación de la política de los permisos no derivaría sólo de la promoción de la igualdad de género, sino también del derecho de los niños a ser cuidados y atendidos por sus padres (Sundström y Duvander, 2002). El supuesto sobre el que se asienta esta política de promoción de los permisos parentales para hombres es que durante el permiso, el padre no se involucra solamente de forma instrumental para resolver tareas, sino también emocionalmente con el niño, lo que sienta las bases para que se dé una mayor dedicación a lo largo de todo su proceso de desarrollo (Tanaka y Waldfogel, 2007; Haas y Hwang, 2008), lo que beneficia tanto a los niños, como promueve una mayor igualdad en el reparto del trabajo no remunerado.

La evidencia empírica de este proceso no es concluyente, aunque buena parte de los estudios disponibles, centrados en la experiencia de los países escandinavos, sí evidencian que existe tal relación, sobre todo cuanto mayor es la duración de los permisos. Este trabajo aporta evidencia adicional en este sentido, no a escala nacional, sino internacional.

Así, un pequeño estudio realizado en Estados Unidos en 1998 a 38 padres con hijos nacidos o adoptados después de 1994, asalariados de grandes compañias o instituciones públicas con edades entre 9 meses y 19 meses, evidencia que, además de haber una proporción importante (alrededor de la mitad) que han interrumpidos durante al menos una semana su trabajo (mediante dias libres, vacaciones o permisos), quienes lo hicieron compartieron más tareas de cuidado de los niños que quienes no lo hicieron, aunque en conjunto no dedicaron más tiempo, ni asumieron en mayor medida la responsabilidad del cuidado de los niños que quienes no lo hicieron (Seward, Yeatts, Amin y Dewitt, 2006). Otro estudio realizado en el Reino Unido a una muestra de 9.592 padres 
de niños de 8 a 12 meses evidencia, por una parte, que una mayoria de padres han utilizado el permiso de paternidad (en la inmensa mayoria de los casos de alrededor de una semana, no estando remunerado) $\mathrm{y}$, por otra, que quienes lo han utilizado están más implicados en distintas tareas de cuidado, aunque no influye en quién tiene la responsabilidad sobre su cuidado (Tanaka y Waldfogel, 2007). Asi, los padres que han utilizado el permiso tienen un 25\% más de probabilidad de haber cambiado pañales, un 19\% más de probabilidad de haber dado de comer al bebé y un 19\% más de probabilidad de haberse levantado por la noche que quienes no utilizaron el permiso. Al mismo tiempo, cuantas más horas trabajan los padres, menor es la probabilidad de realizar estas tareas. Donde mayor evidencia existe de la relación positiva entre permiso parental e implicación en el cuidado de los hijos por parte de los padres es en Suecia, donde se evidencia que, cuando su uso está generalizado como sucede en los países escandinavos en la actualidad, lo relevante no es si se ha utilizado o no, sino el tiempo que se ha disfrutado del permiso.

Así, el estudio de Haas y Hwank (2008), basado en una encuesta a 356 padres varones de hijos menores de 13 años que trabajan en grandes empresas privadas en Suecia (donde el uso de los permisos parentales por los hombres está generalizado, aunque el tiempo de disfrute de los mismos varía mucho), evidencia una relación bastante estrecha entre el número de días de disfrute y su implicación en el cuidado de niños. Utilizando distintos indicadores para medir la implicación del padre en el cuidado de sus hijos, el estudio evidencia que no existe relación entre éstos y el hecho de haber disfrutado o no del permiso. Los padres que han utilizado más días de permiso, sin embargo, es más probable que sean los principales responsables de su cuidado, dediquen más tiempo entre semana a estar con ellos o a hacer cosas con ellos, así como realicen más tareas de cuidado y atención y tengan vínculos más estrechos con sus hijos. 
El trabajo de Duvander y Jans (2009) abunda en la misma dirección, si bien utilizando indicadores diferentes y otra fuente de datos. Basado en una encuesta realizada a 4.000 padres de niños de 3 a 10 años que conviven con éstos, el estudio evidencia que el número medio de horas trabajadas a la semana es menor cuanto más tiempo se haya estado de permiso parental. El supuesto explícito es que los padres más implicados en la crianza de sus hijos adaptan el número de horas trabajadas a su nueva paternidad, por lo que las autoras deducen una relación directa entre duración de los permisos e implicación en el cuidado de los hijos. Este estudio también evidencia que el contacto de los padres separados con sus hijos no convivientes es más frecuente cuanto más tiempo han estado de permiso parental, lo que refleja unos vínculos parentales más estrechos derivados de una mayor implicación en su cuidado y atención.

Basado en la encuesta de empleo del tiempo realizada en Holanda en 2000 y 2005, Versantvoort (2010) observa que los efectos del uso de un permiso parental, esto es, estar en excedencia en el momento de la entrevista (se distingue del permiso de maternidad), incrementa el tiempo dedicado al cuidado de niños en 4 horas semanales y a tareas domésticas en 8 horas en el caso de las mujeres. En el caso de los hombres, por el contrario, no tiene efectos significativos sobre el tiempo dedicado al cuidado de niños, pero sí aumenta en 3,5 horas semanales el tiempo invertido en tareas domésticas. El estudio realizado por Hosking, Whitehouse y Baxter (2010) a partir también de diarios de tiempo, incluyendo tanto dias de la semana como fines de semana, tampoco encuentran relación entre el uso de permisos alrededor del nacimiento del hijo y el tiempo dedicado a los hijos de 4 a 19 meses en Australia. Los padres que interrumpieron su trabajo durante 4 semanas o más no dedicaron más tiempo al cuidado de sus hijos que tienes tomaron permisos más cortos o no los utilizaron. 


\section{Datos y metodologia}

Para analizar los efectos de la utilización de los permisos parentales por los hombres utilizaremos en este trabajo la Encuesta europea de condiciones de trabajo de 2005. Esta encuesta se realiza quinquenalmente por encargo de la European Foundation for Improvement of Living and Working Conditions a una muestra representativa de la población empleada en los 27 países que integran la Unión Europea, así como en Croacia, Noruega, Suiza y Turquia (Parent-Thirion, Macías, Hurley y Vermeylen, 2007). El tamaño de las muestras oscila alrededor de 1.000 personas, si bien en los países más pequeños es de 600; en conjunto el tamaño muestral completo es de 29.680 casos. La submuestra en la que se basa este trabajo es la de padres de hijos menores de 8 años, lo que reduce el tamaño muestral a 6.059 casos. La edad de los hijos hasta la que existe derecho a pedir permisos varía considerablemente de un país a otro. En muchos países llega hasta que los hijos cumplen 8 años, aunque hay trabajadores que pueden ampliar el periodo de disfrute hasta edades de los hijos más avanzadas en virtud de los convenios colectivos que se hayan firmado (habitualmente en la Administración Pública y en las grandes empresas). En determinados casos, como cuando concurren minusvalias u otras circunstancias también se amplía el periodo. En otros, por el contrario, el período de disfrute es más restringido. La desagregación por edades de los hijos de la proporción de personas que han utilizado el permiso parental evidencia que los 8 años es la edad más razonable para hacer el corte. Dado que no se realiza un análisis por países, pues las muestras nacionales son demasiado pequeñas para analizar el fenómeno de forma desagregada, la ponderación utilizada en el análisis es la que neutraliza los sesgos de selección y de no respuesta.

La variable que identifica la utilización de un permiso parental es la respuesta a la pregunta, "q34a_a. In your main paid job, over the past twelve months, have you been absent 
for maternity or paternity leave?” “¿En los últimos doce meses, ha estado ausente de su trabajo remunerado por disfrutar de un permiso de maternidad o paternidad?"). En principio esta pregunta sugiere sólo la utilización de los permisos de maternidad o paternidad, por lo que todas las personas que refieren haber estado ausentes del trabajo por este motivo deberian ser personas con hijos menores de un año de edad (salvo en los muy pocos casos en que el permiso se obtiene por adopción o acogimiento de hijos mayores de dicha edad). Las respuestas proporcionadas por los entrevistados evidencian, sin embargo, que esto es así sólo en el 36\% de los casos; es decir, dos de cada tres entrevistados que han estado ausentes del trabajo por este motivo tienen hijos de uno o más años de edad. Las respuestas incluyen, por tanto, no sólo los casos en los que las personas utilizan permisos de maternidad y paternidad sensu stricto, sino también los permisos parentales (excedencias). Es decir, lo que las respuestas recogen es el uso de los permisos derivados de la tenencia y educación de los hijos, no de un tipo específico de permiso. No obstante, dada la discrepancia entre el literal de la pregunta y las pautas de respuesta, los porcentajes de uso de los permisos pueden estar infravalorados. Lamentablemente no se recoge información sobre la duración del permiso.

La implicación de las personas en el cuidado y educación de los niños se obtiene a través de un indicador subjetivo sobre la frecuencia temporal con la que se produce, estableciéndose como opciones todos los días de la semana 1 hora o más, todos los días o cada dos días menos de 1 hora, una o dos veces a la semana, una o dos veces al mes, una o dos veces al año y nunca. A quienes responden a la primera opción se les pregunta también por el número de horas al día que dedican. Estas mismas preguntas se hacen también para medir la dedicación a las tareas domésticas y cocinar, así como a otras actividades tales como al cuidado de familiares mayores o discapacitados así como a actividades deportivas, culturales y de ocio, que no serán objeto de análisis en este trabajo. 
Ahora bien, la implicación de los hombres en el cuidado de niños y más en general en el trabajo doméstico, y en consecuencia la mayor o menor desigualdad entre los géneros en el espacio doméstico, depende de múltiples factores. Tradicionalmente estos factores se han agrupado en torno a tres enfoques teóricos, a saber: la teoría de los recursos relativos, la teoria de la disponibilidad de tiempo y la teoria de la ideologia de rol (Coverman, 1985; Coltrane, 1996; Bianchi et al., 2000). La teoría de los recursos relativos sostiene que el trabajo doméstico entre los cónyuges se reparte según los recursos de poder (status e ingresos, fundamentalmente) que pueden poder en juego cada una de las partes a la hora de negociar (explícita o implícitamente) los términos de la convivencia y el reparto del trabajo entre la pareja. No se trata solamente de evitar un trabajo no deseado, sino también, desde la argumentación de la teoría económica de la familia (Becker y seguidores), de una asignación eficiente de los recursos temporales escasos de los cónyuges para maximizar el bienestar de la familia. El cónyuge que puede obtener unos mayores ingresos por la venta de su tiempo de trabajo es el que dedica menos tiempo al trabajo no remunerado y se especializa en el trabajo remunerado, maximizando los ingresos de la unidad doméstica. En este sentido, el tiempo dedicado al trabajo doméstico está condicionado por la disponibilidad de tiempo de cada uno de los cónyuges y la carga de trabajo a realizar en el espacio doméstico (fundamentalmente el número de hijos a cuidar y la edad de los mismos). Frente a este planteamiento, que parte del supuesto de la plena capacidad de los individuos para negociar los términos de su convivencia y de la ausencia de roles de género que condicionen la negociación, la teoría de los roles de género parte, por el contrario, del supuesto de que son los roles de género, no sólo de los cónyuges, sino también de los contextos laborales en los que éstos están insertos, los que fundamentalmente explican el desigual reparto del tiempo de trabajo remunerado y no remunerado entre los cónyuges (Duncan y Edwards, 1997; Coltrane, 1996; Duncan et al., 2003). 
La utilización del permiso parental para el cuidado de los niños puede ser así tanto un producto de la negociación de los roles en el seno de la pareja (lo mismo que el tiempo dedicado por los hombres al cuidado de los niños) y por tanto una variable dependiente, como también puede ser una variable independiente que contribuye a explicar la implicación de los hombres en el cuidado de los niños.

En el primer caso, la utilización del permiso parental por parte de los hombres podría ser fruto del mayor poder de negociación de las mujeres a la hora de decidir conjuntamente el reparto del tiempo de cuidado de los niños. Pero también podría ser consecuencia de la materialización de una ideología igualitaria de los padres (varones) y/o de una concepción de la vida más orientada hacia la familia derivada de una forma de entender la paternidad no sólo como "ganapán", sino también como "cuidador", lo que se traduciría también en una menor dedicación temporal al trabajo. En términos de modelo estadístico de análisis, esta interpretación llevaría a que la influencia de la utilización de los permisos parentales en el tiempo dedicado por los hombres al cuidado de los hijos quedaria neutralizada por la influencia de las variables que propician que los hombres se impliquen más en su cuidado. Es decir, la utilización de los permisos sería simplemente una "variable interviniente" y no fomentaria per se la implicación de los hombres en el cuidado de los hijos.

Ahora bien, la utilización del permiso parental por parte de los hombres puede ser no sólo un producto de su falta de poder relativo frente a su mujer y/o un indicador de su ideología de rol igualitaria $\mathrm{y} / \mathrm{o}$ de su concepción "posmoderna" de la paternidad, sino que también puede ser la oportunidad que tienen para establecer lazos más estrechos con sus hijos y vayan construyendo un rol parental más comprometido con el cuidado diario de los hijos, tal como sostiene una de las lineas argumentales de la utilidad social de los permisos parentales sólo para hombres y los 
estudios referidos en el apartado anterior. En este sentido, el uso de los permisos por parte de los hombres no es una variable interviniente, sino un factor propiciador de la mayor implicación de los padres en el cuidado de sus hijos al socializarlos en el rol de cuidadores. Y ello sería así tanto más cuanto mayor sea la duración del permiso, pues la fortaleza de los lazos sociales, el vínculo que une al padre con sus hijos se construye y se retroalimenta a través del contacto continuado en el tiempo.

Resulta imprescindible, por tanto, analizar la influencia del uso del permiso parental sobre la implicación de los padres en el cuidado de los hijos a través de una técnica multivariable en la que se controle la influencia de las variables independientes relevantes para identificar si el uso de los permisos parentales por los hombres promueve realmente una mayor implicación en el cuidado de los hijos, es decir, si tiene efectos independientemente de las características del individuo y de sus condiciones laborales.

Lamentablemente la EWCS 2005 no incluye información sobre el cónyuge más allá de su sexo, edad y relación con la actividad económica, esto es, si tiene un trabajo remunerado o no, por lo que no pueden analizarse los recursos relativos de los cónyuges más allá de que ambos tengan un trabajo remunerado o no. No obstante, y a pesar de que el hecho de que la mujer tenga un trabajo remunerado no siempre aparece como un factor que propicie la implicación de los hombres en las tareas domésticas y en el cuidado de los hijos (Meil, 2005; Pailhé y Solaz, 2008), sobre todo cuando se controla por el nivel profesional y/o ingresos de la mujer (Duvander y Sundström, 2002; Haas y Hwank, 2008), sí se puede y debe controlar por la influencia de que ambos cónyuges tengan trabajo remunerado. En nuestro modelo de análisis multivariable distinguiremos las situaciones en las que ambos cónyuges tienen un trabajo remunerado (asalariado o no) de aquellas en las que sólo lo hace el hombre. Por las características de la encuesta, no se recoge 
información de los casos en los que el hombre no tiene trabajo remunerado y su pareja sí.

Además de si se tiene un trabajo remunerado o no es necesario controlar también por el tiempo "disponible" para el cuidado, entendiendo por tal el tiempo que resta después del trabajo remunerado. Aunque se trata de una construcción ideológica, puesto que el tiempo dedicado al trabajo no sólo viene impuesto al individuo, sino que éste también puede graduarlo a su proyecto vital (aunque con limitaciones importantes), es necesario controlar el número de horas destinadas al trabajo remunerado. De hecho hay estudios que evidencian la influencia de esta circunstancia en el cuidado de los niños: cuantas más horas trabaja el padre, menos se implica en el cuidado de los niños (Meil, 1999; Tanaka y Walfogel, 2007; Duvander y Jans, 2009; Versantvoort, 2010), aunque, al menos en Suecia, los padres que han utilizado el permiso parental, tanto más cuanto mayor es la duración, reducen su tiempo de trabajo tras el nacimiento de sus hijos (Haas y Hwank, 2008; Duvander y Jans, 2009). La variable que utilizaremos en nuestro análisis es el número declarado de horas semanales al trabajo remunerado en todos los empleos que desempeña el entrevistado/a, es decir, incluyendo también el pluriempleo, ordenadas por tramos de 10 horas.

Pero no sólo es relevante el tiempo específicamente dedicado al trabajo, sino que también hay otras circunstancias laborales que condicionan la presencia del padre en el hogar cuando están los niños. Entre estas circunstancias se encuentra el tiempo invertido en la movilidad que el trabajo conlleva y que condiciona también la implicación de los padres en el cuidado de los niños, particularmente en los casos de elevada movilidad (Meil, 2010). Por ello es necesario controlar al menos por el tiempo invertido en los desplazamientos entre el hogar y el trabajo, puesto que otras formas de movilidad (como la frecuencia de pernoctaciones fuera del hogar) no pueden ser analizadas al no haberse recogido información al respecto. En concreto, y tras distintos 
análisis, distinguiremos los casos en los que los padres tienen que invertir 2 horas o más diarias en los desplazamientos al trabajo (ida y vuelta) de los demás casos. Pero además de la movilidad, que "roba" tiempo disponible para dedicarlo a la vida privada, el trabajo en horas denominadas "asociales" (sábados, domingos o por la noche) también puede dificultar la implicación de los padres en el cuidado de los hijos, al no encontrarse en el hogar a las horas en las que éstos habitualmente están. En el modelo de análisis distinguiremos, por tanto, entre padres que trabajan a horas "asociales" de los que lo hacen a horas "normales".

Para medir la sobrecarga relativa se controlará por el número de hijos, agrupando los casos de 4 y más hijos en uno solo (dado que hay pocas familias con más de 4 hijos), así como por la edad del más pequeño, bajo el supuesto de que a mayor número de hijos mayor trabajo y/o cuanto menores sean éstos, mayor será la carga de trabajo y mayor la necesidad de colaboración de ambos cónyuges.

En la EWCS 2005, lamentablemente no se pregunta por la ideología de rol de género de los entrevistados, por lo que no se puede controlar por la influencia de esta circunstancia. No obstante, el nivel educativo se utiliza con frecuencia como variable proxi de la ideología de rol, puesto que los hombres con mayor nivel educativo tienden a identificarse más con los valores de la igualdad de género (Hakim, 2005; Cea d’Ancona, 2007). Según Inglehart (1999) la educación es la fuerza social que se encuentra detrás de la emergencia y difusión de los valores postmaterialistas, valores de carácter más humanístico que se traducen, entre otras, en actitudes más liberales en lo que se refiere a los roles de género y en la difusión de la ideología de igualdad de género a lo largo de la sociedad.

La técnica de análisis estadístico multivariable que utilizaremos será el análisis de regresión logística binomial (Jovell, 1997), que estimará en un primer modelo la razón de probabilidades de que el padre dedique al menos una hora 
diaria al cuidado y educación de los hijos frente a que dedique menos de dicho tiempo, condicionada a las variables anteriormente discutidas. En un segundo modelo se estimará la razón de probabilidades de que dedique también al menos una hora diaria a cocinar y al trabajo doméstico frente a que dedique menos tiempo. Cuando la razón de probabilidades toma el valor 1 significa que la variable independiente no tiene ninguna influencia en la razón de probabilidades. Si toma valores por encima de 1 , implica que aumenta la probabilidad de implicación diaria en el trabajo reproductivo, mientras que si es inferior a 1 , dicha probabilidad disminuye para cada uno de los valores que toma la variable independiente.

\section{El alcance del uso de los permisos parentales en Europa}

El porcentaje de padres (varones) de hijos menores de 8 años que estuvieron ausentes del trabajo en los 12 meses previos a la encuesta por haber hecho uso de los permisos parentales se eleva a un $9 \%$, frente a un $20 \%$ en el caso de las madres. Esta proporción es mayor entre los asalariados que entre los no asalariados, aunque éstos también interrumpen el trabajo con el nacimiento de los hijos o durante su temprana infancia; y no sólo entre las mujeres, sino también en el caso de algunos hombres. Asi, el 4\% de los varones no asalariados refieren haber estado ausentes del trabajo en el año previo a la entrevista por utilizar un permiso parental, frente a un $10 \%$ entre los asalariados. En el caso de las mujeres, los correspondientes porcentajes se elevan al 4 y $21 \%$ respectivamente. El hecho de que los no asalariados también puedan disfrutar de un permiso parental, que en principio sólo estaba restringido a las mujeres asalariadas, no debe extrañar, pues la tendencia hacia la mejora de la cobertura de la protección social a la maternidad y el fomento del uso de los permisos por parte de los hombres ha llevado a que en la legislación de distintos países (sobre todo en los países escandinavos, pero crecientemente también en otros países) se haya previsto también la posibilidad de utilizar permisos (con prestaciones de cuantía fija o sin compensación) en el 
caso de los trabajadores autónomos. Por otra parte, y desde el punto de vista subjetivo de las interpretaciones de los entrevistados, las interrupciones del trabajo con motivo del nacimiento y cuidado de los hijos que refieren los trabajadores autónomos también pueden responder a su concepción de la interrupción de su actividad como utilización de un permiso, aunque estas interrupciones no estén legalmente cubiertas como permisos (Seward, Yeatts, Amin y Dewitt, 2006).

Lo más habitual es interrumpir el trabajo durante el primer año de vida del hijo, no sólo en el caso del permiso de maternidad (donde es obligatoria la utilización del permiso después del nacimiento del hijo) y paternidad, sino también en los casos de las excedencias (Sundström y Duvander, 2002; Geisler y Kreyenfeld, 2011). Así, un 41\% de quienes interrumpieron el trabajo vinculado a un permiso parental tenían hijos menores de 1 año, mientras el resto tenían hijos de un año o más (en un 34\% de los casos el hijo más pequeño tenía 1 año y en el restante $25 \%$ de casos tenía 2 o más años). Esto no significa, sin embargo, que la mayoría de hombres que han sido padres hayan hecho uso de un permiso parental (de paternidad y/o excedencia) durante el primer año de vida del hijo. Únicamente el 32\% de los hombres que han entrado en la paternidad en el año previo a la entrevista y trabajaban disfrutaron de un permiso en 2005 (véase Gráfico1). 
Gráfico 1

Porcentaje de padres (varones) que han interrumpido su trabajo, en los 12 meses anteriores a la encuesta, por maternidad o paternidad en Europa. Año 2005

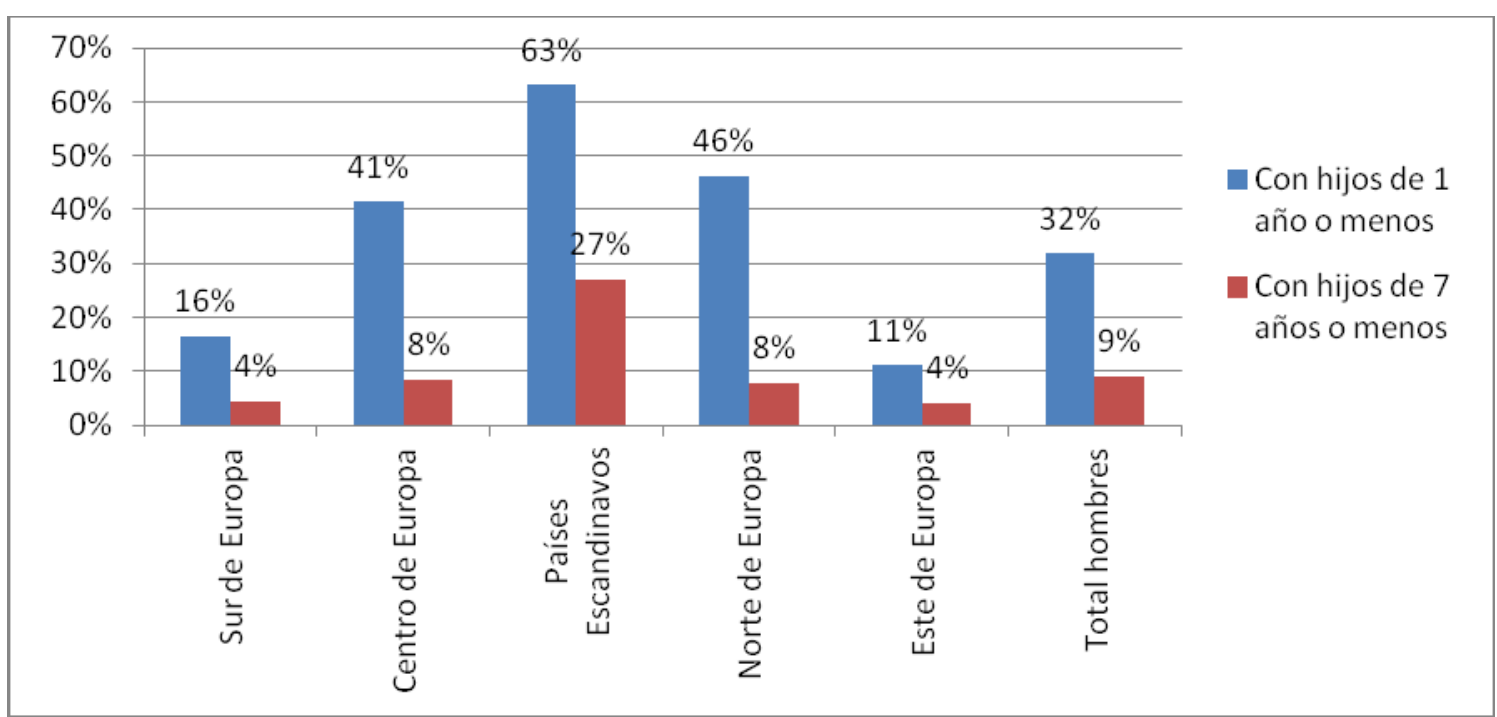

Fuente: elaboración propia de la Encuesta Europea de Condiciones de Trabajo, 2005

Hay, no obstante, grandes diferencias según grupos de países. La mayor incidencia en el uso de los permisos parentales por parte de los padres varones se da, como era esperable, en los países escandinavos, donde un $63 \%$ de los padres de hijos menores de un año han hecho uso del permiso parental frente al $32 \%$ en el conjunto de los países europeos. En los países del este de Europa, por el contrario, es un $11 \%$ y en los del sur de Europa un 16\%. En los países del centro y norte de Europa la proporción se acerca a la mitad de los padres. Si se toma como referencia el conjunto de padres de hijos menores de 8 años, se mantienen básicamente las mismas diferencias, aunque con tasas de incidencia lógicamente menores (véase gráfico 1). Esta diferencia por áreas geográficas responde fundamentalmente al tipo de incentivos para el uso de los permisos que se establecen en los distintos países y esconde grandes diferencias entre unos países y otros, diferencias que no pueden analizarse con la base de datos disponible porque el 
número de casos disponibles para cada país es bajo. El hecho de que los permisos sean remunerados y se enmarquen dentro de una política activa de promoción de la igualdad de género, con fomento explícito y público del uso de los permisos lleva a que el uso por parte de los hombres se desestigmatice y aumente, como puede observarse en los países que han acometido profundas modificaciones en dicha dirección (Duvander, Lappegard y Anderson, 2010; Marshall, 2008; Lammi-Taskula 2008; Geisler y Kreyenfeld, 2011; Moss, 2009).

Tabla 1

Número de horas semanales trabajadas por los padres europeos de hijos menores de 8 años según hayan utilizado un permiso parental en los últimos 12 meses previos a la encuesta.

\begin{tabular}{|l|c|c|c|}
\hline $\begin{array}{l}\text { Horas } \\
\text { semanales de } \\
\text { trabajo }\end{array}$ & $\begin{array}{c}\text { Ha utilizado } \\
\text { permiso } \\
\text { parental }\end{array}$ & $\begin{array}{c}\text { No ha } \\
\text { utilizado } \\
\text { permiso } \\
\text { parental }\end{array}$ & Total \\
\hline $\begin{array}{l}\text { Menos de 35 } \\
\text { h }\end{array}$ & 7 & 6 & 6 \\
\hline 35 a 42 horas & 61 & 52 & 53 \\
\hline $\begin{array}{l}43 \text { horas y } \\
\text { más }\end{array}$ & 32 & 42 & 41 \\
\hline Total & 100 & 100 & 100 \\
\hline
\end{tabular}

$\mathrm{Chi}^{2}$ 23,0 p<0,000

Fuente: elaboración propia de la Encuesta Europea de Condiciones de Trabajo, 2005

Los padres que han utilizado un permiso parental tienden a trabajar menos horas que quienes no lo han hecho, resultado que se ha documentado, como se ha indicado más arriba, también en otros estudios que abordado esta cuestión (Haas y Hwank, 2008; Duvander y Jans, 2009). En conjunto el número de horas que trabajan menos a la semana es de 3,3 horas. Este menor número de horas trabajadas no deriva de un mayor recurso a trabajos a tiempo parcial, sino sobre todo 
porque se reduce sustancialmente la proporción de padres que dedican muchas más horas al trabajo que la que establece la jornada estándar en Europa, tal como puede observarse en la tabla 1.

\section{Los efectos del uso de los permisos parentales sobre la implicación de los padres (varones) en el cuidado de los niños}

La utilización de los permisos parentales por parte de los hombres está asociada con una mayor implicación en el cuidado de niños. Así, mientras el 76\% los padres que refieren haber estado ausentes del trabajo en los 12 meses previos a la encuesta por haber hecho uso de los permisos parentales dedican todos los dias al menos una hora a su cuidado, entre quienes no lo hicieron, dicho porcentaje sólo asciende al $58 \%\left(\mathrm{chi}^{2}=55,3 ; \mathrm{p}<0,000\right)$. Lo mismo sucede con la implicación en las tareas domésticas, aunque los porcentajes son menores, puesto que suponen el 42 y $24 \%$ respectivamente $\left(\mathrm{chi}^{2}=112,2 ; \mathrm{p}<0,000\right)$ (véase Tabla 2$)$.

Por otra parte, el número de horas diario dedicado al cuidado y educación de los hijos entre quienes están implicados al menos una hora al día, también es mayor entre los padres que han utilizado el permiso parental que entre quienes no lo han hecho. Así, la media de horas diarias dedicado al cuidado y educación de los hijos entre los primeros es de 3,36 frente a 3,16 horas, pero esta diferencia además de no ser muy grande no es estadísticamente significativa al nivel convencionalmente aceptado $(F=1,25)$, pero si eliminamos los casos extremos en los que se señala que se dedican las 24 horas del día a su cuidado y educación y establecemos como límite máximo 20 horas, bajo el supuesto de que es frecuente tener que levantarse a la noche, las diferencias se hacen algo mayores. Los padres que han hecho uso del permiso dedican un $10 \%$ más de tiempo que quienes no han utilizado permiso $(3,4$ frente a 3,0 horas diarias $(F=5,02 ; p<0,05)$. En el caso de la dedicación al trabajo doméstico, la utilización del permiso para cuidado de niños no se traduce en una mayor 
dedicación temporal a este tipo de trabajo. De hecho, parece incluso que sucede lo contrario (1,68 frente a 2,03 horas diarias), pero esta diferencia no resulta estadísticamente significativa $(F=3,3)$. Si eliminamos los valores extremos que señalan que dedican las 24 horas del día al trabajo doméstico y establecemos como límite máximo 16 horas, las diferencias se liman algo (1,68 frente a 1,94 horas), pero siguen sin ser estadísticamente significativas $(\mathrm{F}=2,8)$. No puede concluirse, por tanto, que, entre quienes se implican diariamente, la mayor dedicación diaria al cuidado de los hijos derivado del uso del permiso parental se traduzca también en una mayor dedicación al trabajo doméstico, ni que esa mayor dedicación a los niños se compense con una menor dedicación al trabajo doméstico. 


\section{Tabla 2}

Porcentaje de padres de hijos menores de 8 años según la frecuencia de tiempo que dedican al cuidado y educación de los hijos (columnas 2 a 4) y a cocinar y trabajo doméstico (5 a 7) según hayan utilizado o no un permiso parental en el año anterior a la entrevista.

\begin{tabular}{|l|c|c|c|c|c|c|}
\hline & \multicolumn{2}{|c|}{$\begin{array}{c}\text { Cuidado y } \\
\text { educación de los } \\
\text { hijos }\end{array}$} & \multicolumn{2}{c|}{$\begin{array}{c}\text { Cocinar y trabajo } \\
\text { doméstico }\end{array}$} \\
\hline $\begin{array}{l}\text { Utilización de } \\
\text { permiso } \\
\text { parental: }\end{array}$ & Si & No & Total & Si & No & Total \\
\hline $\begin{array}{l}\text { Todos los dias } 1 \\
\text { o más horas }\end{array}$ & $76 \%$ & $58 \%$ & $60 \%$ & $42 \%$ & $24 \%$ & $25 \%$ \\
\hline $\begin{array}{l}\text { Todos los días o } \\
\text { cada dos dias } \\
\text { menos de 1 hora }\end{array}$ & $9 \%$ & $15 \%$ & $14 \%$ & $25 \%$ & $14 \%$ & $15 \%$ \\
\hline $\begin{array}{l}\text { Una o dos veces } \\
\text { a la semana }\end{array}$ & $6 \%$ & $11 \%$ & $10 \%$ & $13 \%$ & $19 \%$ & $18 \%$ \\
\hline $\begin{array}{l}\text { Una o dos veces } \\
\text { al mes }\end{array}$ & $1 \%$ & $2 \%$ & $2 \%$ & $6 \%$ & $9 \%$ & $9 \%$ \\
\hline $\begin{array}{l}\text { Una o dos veces } \\
\text { al año }\end{array}$ & $0 \%$ & $1 \%$ & $1 \%$ & & $3 \%$ & $3 \%$ \\
\hline Nunca & $4 \%$ & $11 \%$ & $10 \%$ & $10 \%$ & $28 \%$ & $27 \%$ \\
\hline $\begin{array}{l}\text { No sabe / no } \\
\text { contesta }\end{array}$ & 4 & 2 & 2 & 4 & 2 & 2 \\
\hline Total & 100 & 100 & 100 & 100 & 100 & 100 \\
\hline
\end{tabular}

Fuente: Elaboración propia a partir de los microdatos de la Encuesta Europea de Condiciones de Trabajo, 2005

En conjunto, no obstante, los padres que han utilizado un permiso parental están más implicados en el trabajo no remunerado (doméstico y de cuidado de los hijos) realizado en el ámbito familiar que quienes no lo han utilizado. Ahora bien, como se ha argumentado más arriba, la implicación de los hombres en el trabajo no remunerado depende de múltiples factores que condicionan en sentido positivo o negativo su implicación, por lo que es necesario realizar un análisis multivariante para controlar si efectivamente la 
utilización de los permisos parentales se traduce en una mayor implicación en el cuidado y atención de los hijos así como en el trabajo doméstico, controlados los efectos de las condiciones laborales y familiares. En la tabla 3 hemos recogido los resultados de la estrategia analítica presentada en el epígrafe metodológico.

\section{Tabla 3}

Razón de probabilidades de que los padres se impliquen diariamente al menos una hora en el cuidado y educación de los hijos (columna 2) y a cocinar y demás trabajos domésticos (columna 3) frente a que lo hagan con menos frecuencia

\begin{tabular}{|l|c|c|}
\hline & $\begin{array}{c}\text { Cuidado y } \\
\text { educación de } \\
\text { hijos }\end{array}$ & $\begin{array}{c}\text { Trabajo } \\
\text { doméstico }\end{array}$ \\
\hline $\begin{array}{l}\text { Ha utilizado permiso parental en } \\
\text { últimos 12 meses }\end{array}$ & $1,73^{* * *}$ & $1,88^{* * *}$ \\
\hline $\begin{array}{l}\text { Número de horas trabajadas } \\
\text { (tramos de 10 horas/semana) }\end{array}$ & $0,78^{* * *}$ & $0,71^{* * * *}$ \\
\hline Trabaja a horas “asociales" & 0,97 & 1,13 \\
\hline $\begin{array}{l}\text { Invierte más de 2 horas en ir y } \\
\text { venir del trabajo }\end{array}$ & $0,70^{* *}$ & 1,00 \\
\hline $\begin{array}{l}\text { Nro. personas a su cargo en el } \\
\text { trabajo }\end{array}$ & 0,86 & 1,01 \\
$\begin{array}{l}\text { De 1 a 4 personas } \\
5 \text { o más }\end{array}$ & $0,77^{*}$ & 0,83 \\
\hline Ambos cónyuges trabajan & $1,63^{* * *}$ & $2,37^{* * *}$ \\
\hline Edad del hijo más pequeño & $0,94^{* * *}$ & $0,91^{* * *}$ \\
\hline Número de hijos & 0,95 & 1,04 \\
\hline Nivel educativo & $1,18^{* * *}$ & $1,23^{* * *}$ \\
\hline Constante & 3,17 & 0,50 \\
\hline$* * *$ p<0,001 ** p<0,01 * p<0,05 & \multicolumn{2}{|l}{} \\
\hline
\end{tabular}

Fuente: Elaboración propia de la Encuesta Europea de Condiciones de Trabajo, 2005

Como se puede observar en la tabla, el haber utilizado un permiso parental por parte de los hombres está asociado con un $73 \%$ más de probabilidad de que se impliquen diariamente en el cuidado y educación de sus hijos, 
controlados los efectos del tiempo invertido en el trabajo y de las condiciones del mismo, así como de sus circunstancias familiares y de pareja y su nivel educativo. El tiempo dedicado al trabajo remunerado también condiciona el tiempo dedicado al cuidado de los niños, de forma que por cada 10 horas de trabajo semanales disminuye la probabilidad de implicarse diariamente al menos una hora en su cuidado en un $22 \%$. En la medida en la que la utilización de permisos tiende a implicar una dedicación menos prolongada al trabajo remunerado, los efectos positivos de la utilización de los permisos en la promoción de la implicación de los padres en el cuidado y educación de sus hijos se refuerzan aún más. A diferencia de lo que han puesto de manifiesto los estudios realizados en Suecia, donde lo relevante no es tanto si se utiliza el permiso o no, sino la duración de los mismos (Haas y Hwank, 2008; Duvander y Jans, 2009), los resultados obtenidos evidencian que la utilización por sí misma, independientemente de la duración (que desconocemos porque no se recogió información al respecto), sí es relevante en la intensidad de la dedicación, al menos en el hecho de que sea diariamente una hora o más. Esta marcada diferencia entre los resultados suecos y los alcanzados a nivel europeo pueden tener su origen en que mientras en Suecia el uso de los permisos parentales por parte de los hombres está generalizado (Duvander, Lappegard y Anderson, 2010), no sucede lo mismo en los países no escandinavos, como se ha visto más arriba.

Además del uso de los permisos parentales, la mayor implicación de los padres en el cuidado de los hijos se da cuando ambos miembros de la pareja tienen un trabajo remunerado y cuanto mayor es su nivel educativo, al tiempo que disminuye cuando el trabajo implica invertir mucho tiempo en desplazamientos diarios así como cuando se tiene una posición de mayor responsabilidad en el trabajo. El hecho de trabajar a horas "asociales" no parece condicionar la frecuencia de cuidado, al menos con el indicador utilizado. A medida que los hijos se hacen mayores también disminuye la proporción de padres que dedican al menos una hora a su 
cuidado y educación. La implicación en el trabajo doméstico está condicionada básicamente por los mismos factores, aunque el hecho de que ambos trabajen tiene una relevancia mucho mayor y el tiempo invertido en desplazamientos no parece ser relevante.

Estos resultados representan correlaciones entre fenómenos, pero no tiene por qué implicar la existencia una relación de causalidad entre utilizar el permiso e implicarse más en el cuidado de los hijos, y es plausible, como señalan Tanaka y Waldfogel (2007), que sean los padres con un modelo de paternidad más implicado y cuidador quienes utilizan los permisos y por ello se implican más en el cuidado, más que como consecuencia de la socialización en el cuidado que pueden promover los permisos parentales. Ahora bien, hay distintas circunstancias que inducen a pensar que existe un efecto socializador o de refuerzo del vínculo. Por una parte, $\mathrm{y}$ aunque de una forma deficiente, se controla por la influencia de la ideologia de rol a través del nivel educativo, que también es significativa, de forma que (como se evidencia en otros estudios) a mayor nivel educativo mayor implicación. Como por otra parte, a mayor nivel educativo mayor dedicación temporal al trabajo remunerado y mayores puestos de responsabilidad en el empleo, al controlarse también estas circunstancias en el modelo multivariable, se aísla la influencia del uso de los permisos de estas circunstancias y puede suponerse cierto efecto socializador en el cuidado de los niños derivado del uso de los permisos parentales. Por otra parte, estos mismos efectos se producen en el ámbito del trabajo doméstico. De hecho, la intensidad del efecto del uso de los permisos en una mayor implicación en el espacio doméstico es algo más intensa, puesto que la probabilidad de dedicar diariamente al menos una hora aumenta un $88 \%$ cuando se ha hecho uso de los mismos y los efectos del tiempo de trabajo son también algo más intensos, pues disminuye un $29 \%$ la participación diaria por cada 10 horas adicionales a las semana de trabajo remunerado. Estos resultados son además muy consistentes, puesto que los niveles de significación son muy bajos $(p<0,001)$. De ahí, que 
pueda suponerse un "efecto socializador" en la igualdad del uso de los permisos parentales por parte de los hombres.

\section{Conclusiones}

En la última década la política social en materia de permisos parentales ha evolucionado en muchos paises de Europa hacia la promoción del uso por parte de los padres varones de dicho permisos. El principal objetivo de esta reorientación es promover una mayor igualdad de género tanto en el mercado de trabajo, al desfeminizar el uso de los permisos y "normalizar" su uso, como en el ámbito doméstico, y en especial para promover una mayor implicación de los padres varones en la crianza de sus hijos. En este artículo hemos analizado la cuestión de si efectivamente el uso por parte de los hombres comporta una mayor implicación del hombre en el cuidado de los hijos y en el trabajo doméstico, utilizando para ello la encuesta europea de condiciones de trabajo de 2005. Esta base de datos, aunque es pequeña para realizar análisis a nivel nacional, tiene la gran ventaja de que proporciona una muestra grande para realizar un análisis conjunto a escala europea, superando así una de las limitaciones que tienen muchos de los estudios nacionales. A pesar de las limitaciones que presenta esta fuente de datos para los objetivos de este trabajo, el análisis realizado evidencia una asociación positiva entre el uso de los permisos y una mayor implicación de los padres en el cuidado de sus hijos y en las tareas domésticas. Este resultado a escala europea se suma a los resultados obtenidos en otras investigaciones realizadas con datos nacionales que también evidencian dicha asociación positiva. A pesar de los problemas para establecer una relación causal incontestable, la utilización de los permisos parentales por parte de los hombres se evidencia así como un mecanismo que facilita una participación más activa de los hombres en el espacio doméstico, tanto en el cuidado y socialización de los hijos como en la realización de los trabajos domésticos, constituyéndose así no sólo en un instrumento para facilitar la difusión de un modelo de paternidad más implicado en la 
socialización de los hijos, sino también en un instrumento para promover una mayor igualdad de género.

\section{Referencias bibliográficas}

Alexander, M.; Whitehouse, G. y Brennan, D. (2011): Australia, en M. Moss (2011): 43-51.

Bianchi, S.; Milkie, M.; Sayer, L. y Robinson, J. (2000): "Is anyone doing the housework? Trends in the gender division of household labor", Social Forces, 79: 191-228.

Burgess, S.; Gregg, P.; Propper, C. y Washbrook, E. (2008): "Maternity Rights and Mothers' Return to Work", Labour Economics 15, 2: 168-201.

Cea d'Ancona, M. A. (2007): La deriva del cambio familiar. Hacia formas de convivencia más abiertas y democráticas, Madrid, CIS, colección monografias 241.

Coltrane, S. (1996): Family Man: Fatherhood, housework and gender equity, Newbury Park, Pine Forge Press.

Coverman, S. (1985): "Explaining husbands' participation in domestic labor", Sociological Quarterly, 26: 81-97.

Duncan, S. y Edwards, R. (1997): "Lone Mothers and Paid Work - Rational Economic Man or Gendered Moral Rationalities?", Feminist Economics, 3, 2: 29-61.

Duncan, S.; Edwards, R.; Reynolds, T. y Allred, P. (2003): "Motherhood, Paid Work and Partnering: Values and Theories", Work, Employment and Society, 17, 2: 309-30.

Duvander, A. Z. y Sundstrom, M. (2002): "Gender division of childcare and the sharing of parental leave among new parents", European Sociological Review, 18, 4: 433-447.

Duvander, A. Z. y Jans, A. (2009): "Consequences of fathers' Parental leave use: evidence from Sweden", en I. Söderling (ed.): Finnish Yearbook of Population Research. Helsinki, The Population Research Institute, pp.51-62. 
Duvander, A. Z.; Lappegard, T. y Andersson, G. (2010): "Family policy and fertility: fathers' and mothers' use of parental leave and continued childbearing in Norway and Sweden", Journal of European Social Policy 2010 20, 1: 45-57.

Einarsdóttir, T. y Pétursdóttir, G. (2011): Island en M. Moss (2011): 139-143.

Escobedo, A.; Flaquer, Ll. y Navarro, L. (en prensa): "The social politics of fatherhood in Spain and France: A comparative analysis of parental leave and shared residence", Ethnologie française.

Geisler, E. y Kreyenfeld, M. (2011): “Against all odds: Fathers' use of parental leave in Germany", Journal of European Social Policy, 21, 1: 88-99.

Haas, L y Hwang, C. Ph. (2008): "The impact of taking parental leave on fathers' participation in childcare and relationships with children: Lessons from Sweden", Community, Work \& Family, 11, 1: 85-104.

Hakim, C. (2005), Modelos de familia en las sociedades modernas. Ideales y realidades, Madrid, CIS, colección monografias 215 .

Hosking, A.; Whitehouse, G. y Baxter, J. (2010): "Duration of leave and resident fathers' involvement in infant care in Australia", Journal of Marriage and Family,72, 2: 1.3011.316.

Inglehart, R. (1999): Modernización and Postmodernización: El cambio cultural, economic y politico en 43 sociedades, Madrid, CIS, colección monografias 161.

Jovell, A. J. (1997): Análisis de regresión logística, Madrid, CIS, cuadernos metodológicos nro. 15.

Kvande, E. (2007), "Leave policy and social inequality: the case of Norway" en Moss y Wall (2007)

Lamb, M.E. (ed.) (1997): The role of the father in child development, Hoboken, John Wiley \& sons. 
Lammi-Taskula, J. (2008): "Doing Fatherhood: Understanding the Gendered Use of Parental Leave in Finland", Fathering 6, 2: 133-148.

Lappegard, T. (2008): "Changing the Gender Balance in Caring: Fatherhood and the Division of Parental Leave in Norway", Population Research and Policy Review 27, 2: 13959.

Lapuerta, I.; Baizán, P. y González, M.J. (2011): "Individual and Institutional Constraints: an analysis of Parental leave use and duration in Spain", Population Research and Policy Review, 30, 2: 185-210.

Marshall, K. (2008): "Fathers' use of paid parental leave", Statistics Canada, Perspectives june 2008 (en línea). http://www.statcan.gc.ca/pub/75-001-x/75-001-x2008106eng.htm, acceso el 15 de septiembre de 2011 .

Meil, G. (1.999): La postmodernización de la familia española, Madrid, editorial Acento.

Meil, G. (2005): "Continuidad y cambio en la división del trabajo doméstico en la familia urbana" en Varios Autores, Estructura y procesos sociales. Libro homenaje a José Cazorla, Madrid, CIS.

Meil, G. (2010): "Job Mobility and Family Life" en N. Schneider y B. Collet (eds.), Mobile Living Across Europe II. Causes and Consequences of Job-Related Spatial Mobility in Cross- National Perspective Opladen, Barbara Budrich Publishers, pp. 217-238.

Moss, P. (ed.) (2008): International Review of Leave Policies and Related Research 2008, Employment Relations Research Series No 100, Department of trade and Industry (en linea), http://www.dti.gov.uk, acceso el 15 de junio de 2011.

Moss, P. (ed.) (2009): International Review of Leave Policies and Related Research 2009, Employment Relations Research Series No 102, Department of trade and Industry (en linea). http://www.dti.gov.uk, acceso el 15 de junio de 2011. 
Moss, P. (ed.) (2010): International Review of Leave Policies and Related Research 2010, Employment Relations Research Series No 115, Department of trade and Industry (en linea). http:/ /www.dti.gov.uk, acceso el 15 de junio de 2011.

Moss, P. y Wall, K. (eds.) (2007), International Review of Leave Policies and Related Research 2007, Employment Relations Research Series No 80, Department of trade and Industry (en linea). http://www.dti.gov.uk, acceso el 15 de junio de 2011.

Moss, P. y O'Brien, M. (2006): International Review of Leave Policies and Related Research 2007, Employment Relations Research Series No 80, Department of trade and Industry (en linea). http://www.dti.gov.uk, acceso el 15 de junio de 2011.

OCDE (1995): "Long-term leave for parents in OECD countries" en Employment Outlook, Paris, OCDE, pp. 171200.

Pailhé, A. y Solaz, A. (2008); "Time with children: Do fathers and mothers replace each other when one parent is unemployed?", European Journal of Population 24, 2: 211236.

Parent-Thirion, A.; Macias, E.; Hurley, J. y Vermeylen, G (2007), Fourth European Working Conditions Survey, Dublin, European Foundation for the Improvement of Living and Working Conditions (en linea), www.eurofound.eu, acceso el 20 enero de 2008.

Seward, R.R.; Yeatts, D.E.; Amin, I. y Dewitt, A. (2006): "Employment leave and fathers' involvement with children: according to mothers and fathers", Men and Masculinities, 8, 4: 405-427

Tanaka, S. y Waldfogel, (2007): "Effects of parental leave and work hours on fathers' involvement with their babies. Evidence from the millennium cohort study", Community, Work and Family, 10, 4: 409-426.

Thomas, J. y Hildingsson, I. (2009): "Who's bathing the baby? The division of domestic labour in Sweden", Journal of Family Studies, 15, 2: 139-152. 
Versantvoort, M. (2010) The impact of leave policies on child care and household work; is there a labelling effect, Universidad de Leiden working paper (en linea). http:/ / media.leidenuniv.nl/legacy / 17-05-2010-versantvoort2010.pdf, acceso el 20 agosto de 2011.

\section{FORMA DE CITAR ESTE TRABAJO EN BIBLIOGRAFÍAS HOW TO CITE THIS ARTICLE IN BIBLIOGRAPHIES}

Meil, G. (2011): “El uso de los permisos parentales por los hombres y su implicación en el cuidado de los niños en Europa", Revista Latina de Sociología, $\mathrm{n}^{\circ}$ 1: 61-97, http://revistalatinadesociologia.com, ISSN 2253-6469 